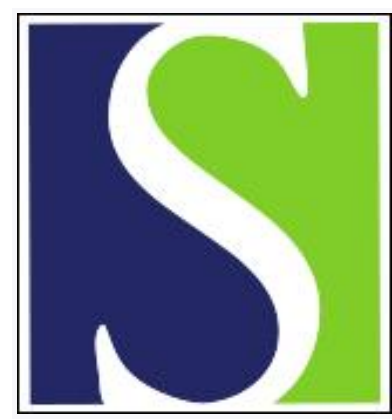

Scand J Work Environ Health 1994;20(4):262-271

https://doi.org/10.5271/sjweh.1399

Issue date: 01 Aug 1994

Retrospective assessment of exposure through modeling in a study on cancer risks among workers exposed to phenoxy herbicides, chlorophenols and dioxins.

by Kauppinen TP, Pannett B, Marlow DA, Kogevinas M

Affiliation: Finnish Institute of Occupational Health, Helsinki.

This article in PubMed: www.ncbi.nlm.nih.gov/pubmed/7801071

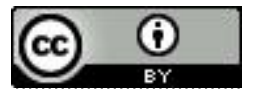




\title{
Retrospective assessment of exposure through modeling in a study on cancer risks among workers exposed to phenoxy herbicides, chlorophenols and dioxins
}

\author{
by Timo P Kauppinen, PhD, ${ }^{1}$ Brian Pannett, MSc, ${ }^{2}$ David A Marlow, BSc, ${ }^{3}$ \\ Manolis Kogevinas, $\mathrm{MD}^{4}$
}

\begin{abstract}
KAUPPINEN TP, PANNETT B, MARLOW DA, KOGEVINAS M. Retrospective assessment of exposure through modeling in a study on cancer risks among workers exposed to phenoxy herbicides, chlorophenols and dioxins. Scand J Work Environ Health 1994;20:262-71.

OвJEctives - The study aimed at developing a model for the retrospective assessment of exposures in epidemiologic studies when little or no data on past exposures are available.

Methons - A deterministic model was developed for the level of exposure by industrial hygienists involved in an international study on cancer risks among phenoxy herbicide or chlorophenol manufacturing workers and pesticide sprayers. The general source-receptor model was used as the conceptual framework for the model.

REsults - The model included variables related to job, the emission of chemicals, contact with chemicals, personal protection, and other relevant determinants of exposure. Cumulative dose indices were calculated from the duration of exposure (from the work histories) and the level of exposure (from the model).

ConCLusions - Deterministic modeling in complex exposure situations may provide more valid and reliable results than its conventional alternative, subjective assessment by an expert.
\end{abstract}

KEY TERMS - dose-response, epidemiology, exposure-response, non-Hodgkin's lymphoma, soft-tissue sarcoma.

\begin{abstract}
Exposure assessment in retrospective epidemiologic studies can be carried out by several methods depending on the resources and information available. The measures of dose chosen, such as cumulative or average exposure, often require an estimation of the level of exposure over time. The more accurate methods of estimating exposure levels use stochastic (statistical) modeling in which missing exposure data are calculated from a model fitted into the results of historical industrial hygiene measurements assumed to follow the log-normal distribution within worker groups defined by plant, job title, and work area. Occasionally the distribution of different tasks within the worker groups is also taken into consideration. Stochastic modeling has been used to study health hazards in the mineral industries (1) and in coal mines (2). If good measurement data are available
\end{abstract}

Finnish Institute of Occupational Health, Helsinki, Finland.

2 Medical Research Council (MRC), Environmental Epidemiology Unit, Southampton, United Kingdom.

3 National Institute for Occupational Safety and Health, Cincinnati, Ohio, United States.

+ International Agency for Research on Cancer, Lyon, France.

Reprint requests to: Dr T Kauppinen, Finnish Institute of Occupational Health, Department of Epidemiology and $\mathrm{Bi}$ ostatistics, Topeliuksenkatu 41 a A, FIN-00250 Helsinki, Finland. only from relatively recent times, a similar procedure can be followed, but any trends in exposure levels over time have to be estimated from knowledge of historical changes in the factors affecting exposure. In some cases, as in studies of silicon carbide workers (3) and railroad workers (4), the level of exposure in the defined worker groups has been assumed to have been constant over time. Exposure to other agents occurring as a measured agent at the same time can be assessed with the use of a conversion factor (5). However, like all group-based assessment methods, stochastic modeling is not able to account for the idiosyncrasies of individual workers. It also tends to be insensitive to exceptional exposure patterns occurring temporarily or occurring in workplaces where industrial hygiene measurements have not been made.

Because comprehensive exposure data are rarely available, less accurate methods have to be employed. If the significant factors determining the level of exposure can be identified, they can be used to construct a deterministic model, which, as a distinction from stochastic models, does not include a random term $(6,7)$. Some models may have both deterministic and stochastic features. For example, a sophisticated stochastic model to estimate exposure to ethylene oxide included factors influencing the level of exposure (8). Even though the deterministic models are generally based on recent measurements, they can be used retrospectively if informa- 
tion about the determinants is available or it can be inferred over time. This approach was used in the reconstruction of exposures in the manufacture of man-made mineral fibers (9). The general idea of deterministic modeling can also be used when only very few data are available. Determinants of exposure can be considered as multiplicative weighting factors, which are applied to the basic level of exposure expressed in absolute or relative units. Often, the basic level is defined by any combination of occupation, task, or plant. This approach has been used to estimate exposures among painters (10), resin manufacturing workers (5), and welders (11). This method, although based on many simplifying assumptions, is more systematic than its conventional alternative, professional judgment, where an industrial hygienist intuitively assigns the levels of exposure case by case in a complex exposure situation.

In this paper we present a deterministic modeling method which was applied to the spraying of herbicides and to the manufacture of phenoxy herbicides and chlorophenols.

\section{Material and methods}

\section{Epidemiologic study}

The International Agency for Research on Cancer (IARC) has compiled a cohort of 21183 workers from 11 countries to study possible cancer risks from phenoxy herbicides, chlorophenols, and their contaminants (12). The results of a mortality and cancer morbidity analysis of the cohort have recently been published (13). The available exposure data, together with information on processes and work environments, have also been summarized $(14,15)$.

The cohort study, which was based on a crude assessment of exposure, was supplemented by a nested case-referent study on soft-tissue sarcomas and non-Hodgkin's lymphomas. Altogether 11 cases of soft-tissue sarcoma and 32 cases of non-Hodgkin's lymphoma were identified from within the cohort, and the patients were each individually matched by gender, age, and country with five referents. The details and results of the epidemiologic study will be published in another paper (in preparation).

\section{General procedure for exposure assessment}

The exposure assessment of the cases and their referents was based on cumulative exposure (CE), defined as a product of the duration of exposure (D) and the estimated level of exposure (L). Exposures occurring five years before selection into the study were ignored in the calculation of the CE scores. Exposures were assessed and ranked by a team of three industrial hygienists unaware of the case-referent status of the subjects. The principles and criteria of exposure assessment were discussed, applied to some typical examples, and agreed upon before the assessment. For consistency, the work was di- vided in such a way that the exposures of all of the cases and referents from a given country were assessed by the same hygienist. The team checked the results, discussed the problems arising during the estimation, and arrived at the final decisions.

The procedure used in the assessment had the following principal steps: qualitative exposure assessment, determination of the duration of exposure, estimation of the level of exposure, calculation of cumulative exposure, and ranking of the subjects (figure 1). Each of the steps is described in more detail in the following sections.

\section{Qualitative exposure assessment}

The assessed agents are shown in table 1. They include phenoxy herbicides, chlorophenols, polychlorinated dioxins and furans, and other agents found in phenoxy herbicide or chlorophenol manufacturing. Some individual agents were grouped for practical reasons. The grouping of agents was mainly based on similarity of chemical structure and expected biological activity. For example, 2,4-dichlorophenoxyacetic acid (2,4-D), 2,4-dichlorophenoxypropionic acid (2,4-DP), and 2,4-dichlorophenoxybutyric acid (2,4-DB) and their salt, amine, and ester derivatives were grouped together on the assumption that their toxic properties relate to the (similar) chlorophenoxy part of these molecules. Chlorinated dioxins and furans were merged because they occur as genuine complex mixtures. Some chemicals, such as 2,4dichloro-, 2,4,5-trichloro-, and methylchloro- derivatives of phenoxy acids, were examined both as individual agents and as grouped into wider categories (phenoxy herbicides) to allow statistical analysis at two hierarchical levels. Nonphenoxy herbicides sprayed or manufactured by the subjects were also recorded qualitatively, but semiquantitative assess-

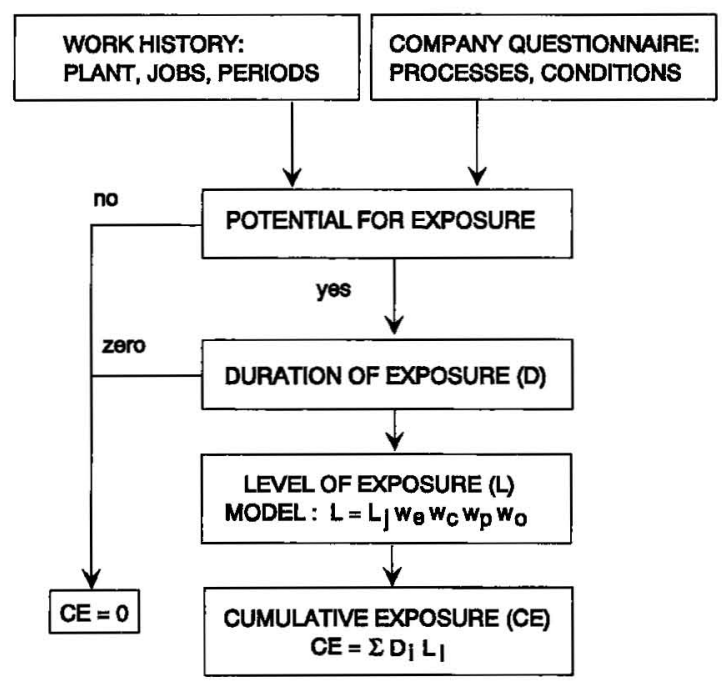

Figure 1. Procedure of the exposure assessment. 
Table 1. Occurrence of chemical agents used in the plants and by the sprayer cohorts involved in the multicentric study, organized by the International Agency for Research on Cancer, on cancer risks among workers exposed to phenoxy acid herbicides, chlorophenols and their contaminants. ${ }^{a}$

\begin{tabular}{|c|c|}
\hline Agent & Occurrence \\
\hline \multicolumn{2}{|l|}{ Phenoxy herbicides } \\
\hline $\begin{array}{l}2,4-\mathrm{D}, 2,4-\mathrm{DP} \text { and } 2,4-\mathrm{DB} \\
2,4,5-\mathrm{T} \text { and } 2,4,5-\mathrm{TP} \\
\text { MCPA, MCPP and MCPB }\end{array}$ & $\begin{array}{l}\text { Manufacture and spraying of } 2,4-\mathrm{D}, 2,4-\mathrm{DP} \text { and } 2,4-\mathrm{DB} \\
\text { Manufacture and spraying of 2,4,5-T and 2,4,5-TP } \\
\text { Manufacture and spraying of MCPA, MCPP and MCPB }\end{array}$ \\
\hline \multicolumn{2}{|l|}{ Chlorophenols } \\
\hline $\begin{array}{l}\text { PCP } \\
\text { TeCP } \\
2,4,5-T C P\end{array}$ & $\begin{array}{l}\text { Manufacture of PCP and by-product in TeCP } \\
\text { Manufacture of TeCP and by-product in PCP and 2,4,6-TCP } \\
\text { Manufacture of 2,4,5-TCP and intermediate in the manufacture of } \\
2,4,5-\mathrm{T} \text { and } 2,4,5-\mathrm{TP}\end{array}$ \\
\hline $\begin{array}{l}2,4,6-\mathrm{TCP} \\
2,4-\mathrm{DCP}\end{array}$ & $\begin{array}{l}\text { Manufacture of } 2,4,6-T C P \text { and by-product in TeCP, } 2,4-D C P \text { and } P C P \\
\text { Manufacture of } 2,4-\mathrm{DCP} \text {, intermediate in the manufacture of } 2,4-D \text {, } \\
2,4-\mathrm{DP} \text { and } 2,4-\mathrm{DB} \text { and by-product in } 2,4,6-\mathrm{TCP}\end{array}$ \\
\hline Polychlorinated dibenzodioxins and furans & $\begin{array}{l}\text { Manufacture of 2,4-D, 2,4-DP, 2,4-DB, 2,4,5-T, 2,4,5-TP and chlo- } \\
\text { rophenols and spraying of 2,4-D, 2,4-DP, 2,4-DB, 2,4,5-T and 2,4,5-TP }\end{array}$ \\
\hline TCDD & $\begin{array}{l}\text { Manufacture of } 2,4,5-\mathrm{TCP}, 2,4,5-\mathrm{T} \text { and } 2,4,5-\mathrm{TP} \text { and spraying of } 2,4,5-\mathrm{T} \\
\text { and 2,4,5-TP }\end{array}$ \\
\hline \multicolumn{2}{|l|}{$\begin{array}{l}\text { Other agents in phenoxy herbicide } \\
\text { or chlorophenol manufacture }\end{array}$} \\
\hline $\begin{array}{l}\text { MCA and MCP } \\
\text { O-Cresol } \\
\text { PCOC } \\
\text { TeCB and TCB } \\
\text { gamma-Butyrolactone } \\
\text { Phenol } \\
\text { Chlorine } \\
\text { Chlorinated aliphatic hydrocarbons } \\
\text { (eg, carbon tetrachloride, trichloroethylene) } \\
\text { Other solvents (eg, toluene, xylene, } \\
\text { alcohols, aliphatic hydrocarbons) }\end{array}$ & $\begin{array}{l}\text { Synthesis of phenoxy herbicides except butyric acid derivatives } \\
\text { Synthesis of PCOC } \\
\text { Synthesis of MCPA, MCPP and MCPB } \\
\text { Synthesis of 2,4,5-TCP and 2,5-DCP, sometimes as solvent in the manu- } \\
\text { facture of phenOxy herbicides and manufacture of other chemicals } \\
\text { Synthesis of MCPB and 2,4-DB } \\
\text { Synthesis of chlorophenols by chlorination } \\
\text { Synthesis of chlorophenols, PCOC, MCA and MCP by chlorination } \\
\text { Sometimes as solvents in synthesis of chlorophenols and phenoxy } \\
\text { herbicides and manufacture of other chemicals } \\
\text { Sometimes as solvents in synthesis of chlorophenols and phenoxy } \\
\text { herbicides, esterification and formulation of phenoxy acids, } \\
\text { formulation of chlorophenols, laboratories and manufacture of other } \\
\text { chemicals }\end{array}$ \\
\hline Nonphenoxy herbicides and pesticides & $\begin{array}{l}\text { Manufacture and spraying of nonphenoxy herbicides and pesticides, } \\
\text { such as triazines, dinoseb, inorganic arsenicals, glyphosate, picloram, } \\
\text { amitrole and organophosphates }\end{array}$ \\
\hline \multicolumn{2}{|c|}{ 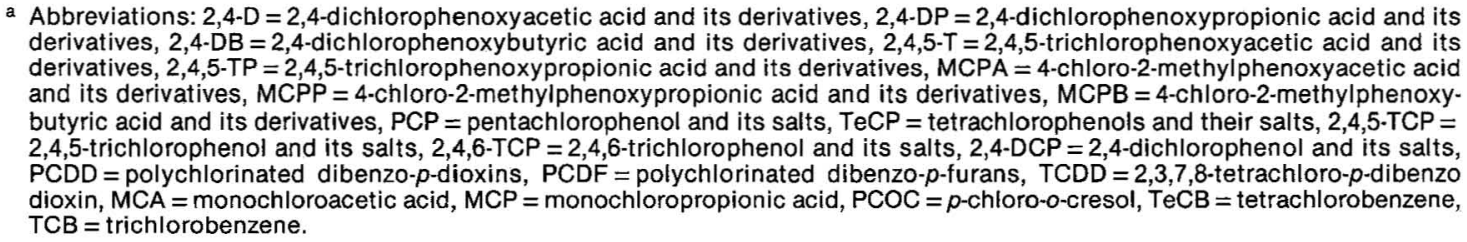 } \\
\hline
\end{tabular}

ment of exposure turned out to be questionable because of the lack of accurate information on periods of exposure.

The occupational histories of the sets of six subjects (one case and five referents - disease status "blinded"), including information about plant or sprayer cohort, departments or jobs, periods of employment, and the end of the assessment period, were used as the basic material. In the qualitative assessment of exposure, unexposed subjects $(L=0, D=0$ and $\mathrm{CE}=0$ ) were identified agent by agent at the cohort level with the help of the company questionnaires and the cross-tabulation of occurrence of exposure by agent and plant or cohort. The following assumptions were made in the assessment: (i) chlorophenols and other raw materials or process chemicals present as impurities in phenoxy herbicide prod- ucts do not entail significant exposure among sprayers and other workers handling phenoxy herbicides only as end products; (ii) significant exposure to 2,3,7,8-tetrachloro-p-dibenzo dioxin (TCDD) among the subjects occurs only in the manufacture or spraying of 2,4,5-trichlorophenoxyacetic acid $(2,4,5-\mathrm{T}), \quad 2,4,5$-trichlorophenoxypropionic acid (2,4,5-TP), and 2,4,5-trichlorophenol (2,4,5-TCP), and (iii) there is no significant carry over of vapors or dusts between production departments unless it is specifically noted in the company questionnaire.

\section{Determination of duration of exposure}

The duration of exposure took into consideration the overlap in the occurrence of exposure and the periods of employment extracted from the detailed work 
records of the subjects under study. It was expressed in years (12 months calculated for each year). For sprayers, the actual length of the spraying time was used whenever available. If the spraying time was unknown, the annual spraying season was assumed to have lasted three months. For some of the potentially exposed subjects, there was no overlap between the occupational history and the occurrence of exposure resulting in assignment to the unexposed category $(D=0, L=0$ and $C E=0)$. To improve the validity of the cumulative exposure, an allowance for a latency period was made by omitting the last five years of the follow-up in the calculation of the duration of exposure.

\section{Estimation of level of exposure}

Biological monitoring is the preferable method for assessing worker exposure to phenoxy acids and chlorophenols. The predominant route of exposure is often through the skin, and air sampling may therefore seriously underestimate exposure. However, it was not possible to estimate the level of exposure accurately because both biological monitoring and industrial hygiene data were rather scarce until the 1980s $(14,16)$.

To obtain semiquantitative estimates of exposure and a reasonable basis for ranking, a simple exposure model was developed. The underlying conceptual framework was the source-receptor model of exposure (17). According to this model the level of exposure is determined by workplace conditions and by the worker's proximity to the source of exposure, which mainly depends on the tasks involved. The "tasks" in the model can be replaced by "job" if the distribution of tasks is similar within the job. The workplace conditions mainly affecting the level of exposure are the rate of emission of contaminant from the source (emission), spread of contaminant due to air movement and surface contamination (transport), and personal protective equipment and work habits (reception). Other factors directly or indirectly influencing the potential for exposure include the size of the workroom, the ventilation systems, the location of the workplace relative to other production areas, the production rate, and health and safety regimes, such as the frequency of plant cleaning. Because a significant part of exposure in this study took place through skin contact, there was no solid basis for accurate calculation procedures, which in some cases may be applied in the estimation of inhalatory exposures. The source-receptor model could therefore be used only as a general guideline and its application took place according to the rules that follow.

In the present study, the characteristics of the job were regarded as the basic factor influencing the estimated level of exposure. In addition, the main factors that significantly modified the basic level were considered to be the emission of agents, the average daily contact time of the workers with the contaminants, the use of personal protective equipment, and certain other factors. These modifying factors were treated as mutually independent and multiplicative weighting factors $(w)$ in the model. The resulting model can be written as follows:

$$
\mathrm{L}=L_{j} w_{e} w_{c} w_{p} w_{o}
$$

(equation 1)

where $\mathbf{L}=$ level of exposure (in relative units), $L_{j}=$ job-related level of exposure, $w_{e}=$ emission factor, $w_{c}=$ contact factor, $w_{p}=$ personal protection factor, $w_{o}=$ other factors.

The job-related levels of exposure $L_{j}$ (table 2) were based mainly on the opinions of the industrial hygiene team and limited exposure data. The IARC

Table 2. Potential exposure by job, and job-related level of exposure $\left(L_{j}\right)$ in relative units. ${ }^{a}$

\begin{tabular}{|c|c|c|c|c|}
\hline Type of work & $\begin{array}{c}\text { Raw materials, } \\
\text { intermediates, } \\
\text { processing } \\
\text { chemicals }\end{array}$ & $\begin{array}{c}\text { Phenoxy } \\
\text { herbicides or } \\
\text { chlorophenols }\end{array}$ & $\begin{array}{c}\text { Other agents } \\
\text { formulated } \\
\text { or sprayed }\end{array}$ & $\begin{array}{c}\text { Job-related } \\
\text { level of } \\
\text { exposure } \\
\left(L_{j}\right)\end{array}$ \\
\hline \multicolumn{5}{|l|}{ Manufacture } \\
\hline $\begin{array}{l}\text { Synthesis } \\
\text { Finishing } \\
\text { Production (unspecified) } \\
\text { Formulation } \\
\text { Packing } \\
\text { Maintenance } \\
\text { Plant cleaner } \\
\text { Supervisor } \\
\text { Laboratory } \\
\text { Effluent/waste plant } \\
\text { Shipping } \\
\text { Other exposed by proximity }\end{array}$ & $\begin{array}{l}\text { Yes } \\
\text { Yes } \\
\text { Yes } \\
- \\
\bar{Y} \\
\text { Yes } \\
\text { Yes } \\
\text { Yes } \\
\text { Yes } \\
- \\
-\end{array}$ & $\begin{array}{l}\text { Yes } \\
\text { Yes } \\
\text { Yes } \\
\text { Yes } \\
\text { Yes } \\
\text { Yes } \\
\text { Yes } \\
\text { Yes } \\
\text { Yes } \\
\text { Yes } \\
\text { Yes } \\
\text { Yes }\end{array}$ & $\begin{array}{l}- \\
- \\
\text { Yes } \\
\text { Yes } \\
\text { Yes } \\
\text { Yes } \\
\text { Yes } \\
\text { Yes } \\
\text { Yes } \\
\text { Yes }\end{array}$ & $\begin{array}{r}10 \\
10 \\
7 \\
5 \\
5 \\
3 \\
3 \\
2 \\
1 \\
1 \\
1 \\
1\end{array}$ \\
\hline \multicolumn{5}{|l|}{ Spraying } \\
\hline Sprayer & - & Yes & Yes & 10 \\
\hline
\end{tabular}

\footnotetext{
a The exposure status stated is a guideline. Exceptions were made in some cases.
} 
company questionnaire also included a request to rank departments and jobs according to the level of exposure to polychlorinated dibenzo-p-dioxins (PCDD) and polychlorinated dibenzo- $p$-furans (PCDF), but replies were obtained only from a few plants. No direct exposure data were available from most of the plants and cohorts, and therefore general data reported in the literature were mainly used. The exposure of phenoxy herbicide applicators was studied rather extensively in the $1980 \mathrm{~s}$, and the mean concentrations of phenoxy acids in urine usually ranged from $<1$ to $8 \mathrm{mg} \cdot \mathrm{l}^{-1}$. Exposure of forestry workers was usually heavier than that of agricultural workers. Exposure of manufacturing workers to phenoxy herbicides has been monitored by biological samples only in one plant not included in this study. The urine samples of formulation workers contained an average of $1.4 \mathrm{mg} \cdot \mathrm{l}^{-1}$ of $2,4-\mathrm{D}$. In one tetrachlorophenol plant included in this study the mean concentration of chlorophenols in the urine of synthesis workers was $2.3 \mathrm{mg} \cdot \mathrm{l}^{-1}$, and in the urine of packers it was $1.9 \mathrm{mg} \cdot 1^{-1}$. The mean concentrations of pentachlorophenol reported from four pentachlorophenol plants not included in this study ranged from $<1$ to $2.4 \mathrm{mg} \cdot \mathrm{l}^{-1}$ among unspecified production workers, but the analytical method used probably underestimated the exposure. Because phenoxy herbicides and chlorophenols can be absorbed by the skin, the results from air samples available from several plants were not regarded as reliable in the setting of the $L_{j}$ values. In addition, levels of TCDD below the parts per billion range have been measured in the serum of workers exposed to phenoxy herbicides or chlorophenols. The exposure data have been described in more detail elsewhere $(14,16)$.

Different tasks within a job can entail different levels of exposure. Because almost no information was available about the proportional distribution of tasks, the possible variation of tasks between workers of the same job group could not be taken into account, and only one basic value was used for each job. The departments and jobs for which exposure was estimated to be low were given the relative value of 1 . On the basis of available exposure data, the highest potential for exposure was considered to have occurred among synthesis workers, finishing workers, and herbicide sprayers, and they were given the value 10. Other exposed jobs were distributed according to the evaluation of the team between these two extreme values. In the special case in which workers were rotated between several operations or departments and the work histories did not allow discrimination between different work periods, $L_{j}$ was calculated as the time-weighted average. For example, if a worker shared evenly the workhours between synthesis $\left(L_{j}=10\right)$ and formulation $\left(L_{j}=5\right), L_{j}=7.5$ for agents present in both operations, $L_{j}=5$ for agents present only in synthesis, and $L_{j}=2.5$ for agents present only in formulation.
It was assumed that the $L$ of a given job, which is predominantly determined by the work tasks and proximity of the worker with the emission sources, was independent of the calendar time and constant in all situations. The agent-, plant- and time-specific factors were considered to affect the modifying weight factors $w_{e}, w_{c}, w_{p}$, and $w_{o}$. Stepwise changes in the weight factors resulted in corresponding changes in the estimated level of exposure, and therefore for each plant-job combination a separate L-profile over calendar time was derived. Because the units used were relative, the values of $L_{j}$ (and consequently of $L$ and $C E$ ) are mutually comparable and additive only for those agents for which $L_{j}$ was based on biological monitoring data (ie, for phenoxy herbicides and chlorophenols).

The emission factor $w_{e}$ was assumed to be 1 unless there was good reason to believe, on the basis of the company questionnaire or other reliable sources of information, that the emissions in the plant were significantly higher or lower on the average than in other manufacturing plants. Examples of situations in which the value of $w_{e}$ differed from unity follow: (i) shift from an old plant to a new plant assessed, on the basis of information provided by the company, to have a more-enclosed process $\left(w_{e}=0.5\right.$ for the process workers during the period when the new plant was in operation); (ii) manual charging or discharging of reaction vessels $\left(w_{e}=2\right.$ for the synthesis workers during the period of manual work); (iii) dusty conditions arising from bagging ( $w_{e}=2$ for packers during the dusty period); (iv) process accident releasing TCDD or the occurrence of several cases of chloroacne $\left(w_{e}=5\right.$, cases of chloroacne, or 10, TCDD-releasing accident, in the contaminated departments from the time of the accident or of the occurrence of chloroacne cases until the shutdown or thorough cleanup of the process); past experience has shown that accidents in which process material contaminated with TCDD has been released into the work environment have resulted in a high incidence of chloroacne among the workers involved (18-22).

The production volumes of chemicals were available from most plants, but their use in the estimation was discarded because interaction with other determinants of exposure was suspected. If several emission factors applied simultaneously, they were multiplied to obtain the total $w_{e}$.

The contact factor $w_{c}$, describing mainly the proportion of the workhours spent with specific exposure, was considered to be necessary because the plants usually manufactured several types of herbicides, chlorophenols, and other chemicals simultaneously. Similarly, herbicide sprayers also used nonphenoxy herbicides and other pesticides. The amounts of individual agents synthesized or sprayed varied significantly over time and plant. The mean proportion of the workday spent in contact with different types of chemicals could be crudely inferred on the basis of the company questionnaires which 
included information about the distribution of the workhours by product and the production volumes by product in five-year intervals. Another factor that restricted the contact of the workers with the process emissions was the development of automatic process control, which tended to move workers from the vicinity of the emissions mainly into ventilated control rooms. Examples of the values used for $w$ follow: (i) $10 \%$ of workhours spent in synthesis of a specific herbicide $\left(w_{c}=0.1\right.$, ie, $\left.10 \%\right)$ and (ii) most of the time spent in a ventilated control room $\left(w_{f}=0.5\right)$.

Local ventilation was discussed as a determinant, but there were no cases in which the documentation would have warranted the use of a decreased value for $w_{c}$. If several contact factors applied simultaneously, they were multiplied to obtain the total $w_{c}$.

Because the company questionnaires did not usually contain any quantitative data on raw materials, process chemicals, intermediates or impurities, the $w_{c}$ for these chemicals had to be inferred from the production volumes of phenoxy herbicides or chlorophenols and from the process descriptions. A set of rules was made for the inference of $w_{c}$. Examples follow: (i) $w_{c}$ for TCDD equals either $w_{c}$ for 2,4,5-T and 2,4,5-TP in phenoxy plants and spraying, or $w_{\text {c }}$. for 2,4,5-TCP in chlorophenol plants because TCDD is present in these products; (ii) $w_{c}$ for PCDD and PCDF equals either the summed $w_{c}$ for all phenoxy herbicides except methylchlorophenoxy acetic, propionic or butyric acid (MCPA, MCPP, or MCPB) in phenoxy plants and spraying or the summed $w_{c}$ for penta-, tetra- and trichlorophenols in chlorophenol plants because PCDD and PCDF are present as impurities in these products; (iii) $w_{c}$ for $p$-chloro-ocresol (PCOC) equals $w$ for MCPA, MCPP, and MCPB in phenoxy plants because PCOC is their raw material; (iv) $w_{c}$ for gamma-butyrolactone equals the summed $w$ for MCPB and 2,4-DB in phenoxy plants because it is their raw material; (v) $w_{c}$ for phenol equals either $w_{c}$ for 2,4-D, 2,4-DP, and 2,4-DB in phenoxy plants or the summed $w_{e}$ for chlorophenols in chlorophenol plants applying the chlorination process because phenol is the raw material of these products.

The personal protection factor $w_{p}$ was assessed from the information provided by the company questionnaires. The use of respirators or protection of the skin was uncommon in manufacturing plants, except during some short-term tasks with high potential for exposure. In spraying, the use of personal protection had probably increased slightly over the years. Applying the value of 0.5 for $w_{p}$, when appropriate protective equipment of the skin and respiratory tract were frequently used, was discussed, but inaccurate documentation of worker protection in the company questionnaires did not warrant the use of this value.

All other factors deemed to exert a significant effect on the level of exposure were incorporated into $w_{i}$. Health concerns and the start of biological mon- itoring in some plants and subcohorts have probably decreased exposure since the mid-1970s through small improvements in the area of personal hygiene, the handling of chemicals, and the cleaning of the work environment. Another significant change concerns the level of exposure to polychlorinated dioxins and furans. In many manufacturing plants, process parameters have been adjusted to minimize the sidereactions in which these toxic compounds are formed. Their concentrations in the end products have consequently decreased. The values used for $w_{o}$ were the following: (i) for compounds other than TCDD and PCDD and PCDF in manufacturing plants $w_{o}=1$ before $1975, w_{o}=0.75$ in $1975-1980$, and $w_{o}^{o}=0.5$ after 1980 and (ii) for TCDD and PCDD and PCDF in manufacturing plants and spraying $w_{o}=1$ before $1970, w_{o}=0.5$ in $1970-1980$, and $w_{o}^{o}=0.25$ after 1980 . A small computer program was used to calculate the total $w_{i}$.

\section{Calculation of cumulative exposure and the ranking of the subjects}

The final exposure index was calculated as cumulative exposure (CE) summed over all the different jobs held by the subject for all periods of exposure:

$$
\mathrm{CE}=\sum_{i=1}^{\mathrm{n}} D_{i} L_{i}
$$

(equation 2)

where $D_{i}=$ exposure period (in years) during which the level of exposure of the subject was $L_{i}$, and $L_{i}=$ level of exposure during the exposure period $D_{i}$.

Cumulative exposure was calculated by a computer program ignoring exposure for the last five years before selection into the case-referent study. For example, let us consider a worker who worked from 1 January 1960 to 1 July 1983 in the synthesis department of a plant (ie, $L_{i}=10$ ), which manufactured phenoxy herbicides including $2,4-\mathrm{D}$ ( $40 \%$ of all phenoxy herbicides; ie, $w_{c}=0.4$ ). Production was shifted to a new plant with more-closed process equipment (ie, $w_{e}$ changes from 1.0 to 0.5 , and the level of exposure drops) on 1 January 1975, and since then exposure has decreased gradually (a general assumption concerning all plants; ie, $w_{o}=0.75$ in $1975-$ 1980). No personal protection equipment was regularly used (ic, $w_{p}=1$ ). If this worker was followed until 1 January 1985 , the calculation of D and CE for exposure to 2,4-D would proceed as follows:

$\mathrm{D}=D_{1}+D_{2}=15+5=20$ years (two periods with different $L ; 1980-1983$ discarded because of a five-year lag period),

$L_{t}=L_{j} w_{c} w_{c} w_{p} w_{o}=10 \times 1 \times 0.4 \times 1 \times 1=4.0$ (from 1 January 1960 to 31 December 1974),

$L_{2}=10 \times 0.5 \times 0.4 \times 1 \times 0.75=1.5$ (from 1 January 1975 to 31 December 1979), 
Table 3. Exposure characteristics of the referents of the study. The figures are mean values omitting exposure during the last five years before the end of the follow-up. The scores, except those of the duration of exposure, are not mutually comparable because the level has been expressed in agent-specific relative units. ${ }^{a}$

\begin{tabular}{|c|c|c|c|c|}
\hline Agent & $\begin{array}{c}\text { Prevalence } \\
\text { of exposure } \\
(\%)\end{array}$ & $\begin{array}{c}\text { Duration of } \\
\text { exposure } \\
\text { (years\} }\end{array}$ & $\begin{array}{l}\text { Level of } \\
\text { exposure } \\
\text { (unitless) }\end{array}$ & $\begin{array}{c}\text { Cumulative } \\
\text { exposure } \\
\text { (level-years) }\end{array}$ \\
\hline $\begin{array}{l}2,4-D, 2,4-C P \text { and } 2,4-D B \\
2,4,5-T \text { and } 2,4,5-T P \\
\text { MCPA, MCPP and MCPB } \\
\text { PCP } \\
\text { TeCP } \\
2,4,5-T C P \\
2,4,6-T C P \\
2,4-D C P \\
\text { PCDD and PCDF } \\
\text { TCDD } \\
\text { MCA and MCP } \\
\text { o-Cresol } \\
\text { PCOC } \\
\text { TeCB and TCB } \\
\text { gamma-Butyrolactone } \\
\text { Phenol } \\
\text { Chlorine } \\
\text { Chlorinated aliphatic hydrocarbons } \\
\text { Other solvents }\end{array}$ & $\begin{array}{r}38 \\
23 \\
50 \\
4 \\
3 \\
9 \\
6 \\
15 \\
48 \\
25 \\
28 \\
23 \\
25 \\
3 \\
2 \\
15 \\
30 \\
13 \\
20\end{array}$ & $\begin{array}{l}6.5 \\
8.0 \\
5.0 \\
9.9 \\
7.1 \\
4.1 \\
4.8 \\
7.9 \\
6.4 \\
8.1 \\
4.7 \\
4.9 \\
4.3 \\
5.8 \\
2.1 \\
8.8 \\
5.8 \\
3.1 \\
5.0\end{array}$ & $\begin{array}{l}1.6 \\
1.6 \\
2.6 \\
4.7 \\
4.5 \\
3.8 \\
1.3 \\
0.8 \\
3.4 \\
1.9 \\
4.3 \\
3.8 \\
4.0 \\
2.2 \\
1.9 \\
3.4 \\
5.5 \\
4.8 \\
1.5\end{array}$ & $\begin{array}{r}10.1 \\
13.0 \\
13.1 \\
46.2 \\
31.9 \\
15.5 \\
6.4 \\
6.0 \\
21.6 \\
15.5 \\
20.2 \\
18.7 \\
17.3 \\
12.5 \\
4.0 \\
29.8 \\
31.7 \\
14.9 \\
7.5\end{array}$ \\
\hline
\end{tabular}

a For the abbreviations, see the footnote of table 1.

and

$\mathrm{CE}=D_{1} L_{1}+D_{2} L_{2}=15 \times 4.0+5 \times 1.5=67.5$ level years.

The calculated mean values of cumulative exposure, the estimated level of exposure, and the duration of exposure of the exposed referents of the study are presented in table 3 . The CE scores were then used in the statistical analysis both as continuous and categorical variables. Subjects within each matched set were also ranked so that the person with the highest cumulative exposure within the set was given the rank of one and the lowest the rank of six. To avoid a misclassification of exposure, similar ranks were given to all of the unexposed persons $(\mathrm{CE}=0)$, all persons with light exposure (CE nonzero but $<1$; corresponding maximally to one year of exposure at the level $\mathrm{L}=1$ ), and those whose $\mathrm{CE} \geq 1$, but differed by less than $50 \%$ from the CE of subjects with adjacent ranks.

\section{Discussion}

The validity of the exposure estimates requires that the measure of exposure and the model are correct and that the estimation is accurately carried out. $\mathrm{Cu}-$ mulative exposure in its simplest form (level times duration) assumes inherently a linear relation between exposure and outcome, which in addition is independent of time. It may therefore be criticized as the measure of dose because the outcome under study may be nonlinear and depend on the time elapsed since first exposure (23). We allowed a fiveyear latency period for the cancers studied and thus omitted the most recent exposures. There are more sophisticated approaches with which to weigh the time since first exposure, but adopting them, as well as weighing the possible nonlinearity, would have been questionable because of the lack of information concerning the mechanisms of occupational carcinogenesis concerning non-Hodgkin's lymphomas and soft-tissue sarcomas. Cumulative exposure omitting the last five years before the end of the follow-up was chosen because it was a feasible measure to be estimated and there was no solid basis for using more complex measures.

An effort was made to take into account the most significant factors and temporal changes in the exposure conditions through the introduction of timedependent weighting factors. Because there was no "gold standard" (criterion) to compare with, it was impossible to measure to what extent this attempt was successful. However, each step of the assessment was considered by a team of experienced industrial hygienists and included in the model only if it was agreed that the incorporation improved the validity of the estimates. It is probable that this method provided more accurate exposure estimates than the method used in the corresponding cohort study (15), because temporal and plant-specific factors could be more fully utilized. Comparison of the results of the case-referent studies and the cohort study can also be used as an internal validity test of the modeling method. The findings of the studies agreed to a large extent, but the magnitude of the risk in the case-referent studies was higher and therefore indicated that this exposure assessment exercise managed to remove some of the nondifferential misclassification and thus provided more statistically significant results.

Some factors that may have been important could not be considered at all due to the lack of sufficient information. One was the variation of exposure be- 
tween workers employed in the same job. For example, the mean concentration of chlorophenols in the urine of synthesis workers varied about twofold and that of the packers about tenfold in one of the chlorophenol plants under study (14). Between-worker variability of exposure in various other jobs has been reported to range from under twofold to over 1000fold (median about 25 -fold when $5 \%$ of the values were excluded as outliers) (24). Omitting this factor may have caused misclassification, which in most cases tends to bias the point estimates of risk towards unity (misclassification between the exposed and unexposed) and to diminish the exposure-response relation (misclassification between the exposed classes).

Another assumption of the model was that the factors incorporated were independent (ie, a change in one factor did not automatically influence the values of other factors). Any interactions between factors would lead to over- or underestimation, which should be corrected by adding interaction terms into the model. The basic factors of the model - job characteristics, emissions, transport, and reception can be considered to be relatively independent, and no significant interactions were identified by the team during the assessment. Of the possible determinants, only the production volume was considered as reasonable to discard because it was known in some plants to be related to the changes in shift-work schedules and also to the proportion of workhours spent in contact with chemicals (incorporated into $w_{c}$ ). The information obtained regarding historical changes in workhours and shift systems was not accurate enough to warrant the use of a weighting factor in this study. However, in situations in which more complete information is available, the effect of production volume could be incorporated. Relationships have been found between production rate and exposure levels (25).

One critical point in this estimation procedure is the assignment of the job-related levels ( $L$ values in table 2). The setting of these values was based on the judgment of the team and rather limited data on exposure. Another team with different experience may have assigned different values and thereby influenced the final exposure estimates. In addition, the same basic level was applied independently of the plant and country. It is possible that, for example, laboratory workers may have rather high exposure in plants where their tasks include manual sampling of the process streams and products. We tried to overcome this difficulty by matching the country, which in many cases meant also matching the plant and comparing with each other only subjects who had worked in the same plant. However, if enough information is available on the tasks or ranks of jobs in the studied plants, a better procedure might be to assign plant-specific $L_{j}$ values.

The degree of certainty of the different factors used in deriving exposure estimates varies by factor and agent. The duration of exposure was usually a precise measure based on individual work histories and plant information. The level of exposure was derived from a group-based model, in which the contributing factors were all relatively crude estimates. The uncertainty of the level is also reflected in the cumulative exposure. However, what cumulative indices lose in certainty, they win in validity. Using only the duration of exposure as the measure of exposure would mean omitting often over 100 -fold level-related exposure differences between worker groups. The estimates for phenoxy herbicides, chlorophenols, and their dioxin or furan impurities are also likely to be more accurate than those for other pesticides and solvents, because the company questionnaires provided more-detailed information on them.

The ranking system, which was used together with continuous and grouped CE scores, also deserves a critical comment. One advantage of using ranks is that it provides an alternative for examining the data to ensure that the findings are robust and do not depend highly on ways of categorizing data. Another advantage is that there is the possibility of expressing an uncertainty factor concerning the calculation of the exposure scores, by allocating the same rank value for subjects with approximately similar CE scores. On the other hand, deriving ranks from $\mathrm{CE}$ scores means replacing the best estimates by cruder values. The $\mathrm{CE}$ scores estimating the true quantity of exposure become ordinal ranks, and the possible exposure-response relation becomes distorted. In the present study, both approaches provided results that were essentially similar in relation to the direction of the odds ratios and the statistical significance of the associations. Hardly any new information was gained by ranking when it was used in connection with the more-accurate procedure based on cumulative exposure.

Simultaneous exposure to many agents, which has been described in more detail in another paper (14), was common in the study population, as is illustrated in table 4. Table 4 lists the Pearson correlation coefficients of the $\log \mathrm{CE}$ scores (individual scores as continuous variables) for selected pairs of agents among all of the referents $(\mathrm{N}=213)$ involved in the nested case-referent study of IARC. In a complex situation like this, confounding may occur. Should there be an agent causing the risk, its correlations will also show a spurious excess in the analysis. The modeling method may slightly decrease this kind of confounding bias because it decreases misclassification of the agent and confounders. Control of confounding by stratification or statistical modeling of the studied associations can be used, but residual confounding may still be left, especially if the agents are strongly correlated. However, confounding requires that the confounding agent is also associated with the disease under study. The epidemiologic study found significant associations in relation to exposure to 
Table 4. Pearson correlation coefficients between the log cumulative exposure scores for selected chemical exposures among all referents of the study. ${ }^{\mathrm{a}}$

\begin{tabular}{|c|c|c|c|c|c|}
\hline Agents & $\begin{array}{c}2,4-D, \\
2,4-D P \\
\text { and } 2,4-D B\end{array}$ & $\begin{array}{c}2,4,5, \mathrm{~T} \\
2,4,5-\mathrm{TP} \\
\text { and MCPB }\end{array}$ & $\begin{array}{c}\text { MCPA } \\
\text { and MCPP }\end{array}$ & $\begin{array}{c}\text { PCDD } \\
\text { and PCDF }\end{array}$ & TCDD \\
\hline $\begin{array}{l}2,4-\mathrm{D}, 2,4-\mathrm{DP} \text { and } 2,4-\mathrm{DB} \\
2,4,5-\mathrm{T} \text { and } 2,4,5-\mathrm{TP} \\
\mathrm{MCPA}, \mathrm{MCPP} \text { and MCPB } \\
\text { PCDD and PCDF } \\
\text { TCDD }\end{array}$ & 1 & $\begin{array}{l}0.67 \\
1\end{array}$ & $\begin{array}{l}0.74 \\
0.35 \\
1\end{array}$ & $\begin{array}{l}0.72 \\
0.68 \\
0.44 \\
1\end{array}$ & $\begin{array}{l}0.56 \\
0.90 \\
0.24 \\
0.73 \\
1\end{array}$ \\
\hline
\end{tabular}

a For the abbreviations, see the footnote of table 1 .

phenoxy herbicides and dioxins, but not in relation to other chemicals. Apart from some highly correlated agents in table 4, other agents can therefore probably be disentangled without a significant confounding bias.

In summary, simple deterministic modeling of exposure is a procedure which can be applied in the retrospective assessment of exposure in industrybased studies when few data on the levels of exposure are available. The results are likely to be less valid than assessment procedures based on a comprehensive set of measurements, but more valid and reliable than the subjective assessment by an expert. The procedure requires knowledge of the industry under study for the development and use of the exposure model. Confounding due to the simultaneous presence of many etiologic agents may only slightly be influenced by exposure modeling, but calculating intercorrelations of agents highlights such possibilities and may thus help in the interpretation of the results of epidemiologic studies. Misclassification of exposure is unavoidable, but its effect can be reduced by matching on the country level and by using standard rules for classifying subjects within each matched set. Although the present model was constructed mainly for the chemical industry, its starting point was the general source-receptor model, which is applicable to a wide range of industries and operations, provided that the factors of the model take into account the specific characteristics of exposure in the jobs being studied.

\section{Acknowledgments}

We wish to thank Ms R Winkelmann from IARC for her skillful data management during this project and the internal reviewers of the National Institute for Occupational Safety and Health in the United States for their very valuable comments on the manuscript.

\section{References}

1. Rice C, Harris RL, Lumsden J, Symons M. Reconstruction of silica exposure in the North Carolina dusty trades. Am Ind Hyg Assoc J 1984;45:689-96.

2. Seixas NS, Moulton LH, Robins TG, Rice CH, Attfield MD, Zellers ET. Estimation of cumulative expo- sures for the national study of coal workers' pneumoconiosis. Appl Occup Environ Hyg 1991;6:1032-41.

3. Smith TJ, Hammond SK, Laidlaw F, Fine S. Respiratory exposures associated with silicon carbide production: estimation of cumulative exposures for an epidemiological study. Br J Ind Med 1984;41: 100-8.

4. Woskie SR, Smith TJ, Hammond SK, Schenker MB, Garshick E, Speizer FE. Estimation of the diesel exhaust exposures of railroad workers: II. national and historical exposures. Am J Ind Med 1988;13:395404.

5. Dosemeci M, Stewart PA, Blair A. Three proposals for retrospective, semiquantitative exposure assessments and their comparison with the other assessment methods. Appl Occup Environ Hyg 1990;5:52-9.

6. Schneider T, Olsen I, Jorgensen O, Lauersen B. Evaluation of exposure information. Appl Occup Environ Hyg 1991;6:475-81.

7. Yu RC, Tan WY, Mathew RM, Andjelkovich DA, Levine RJ. A deterministic mathematical model for quantitative estimation of historical exposure. Am Ind Hyg Assoc J 1990;51:194-201.

8. Greife AL, Hornung RW, Stayner LG, Steenland KN. Development of a model for use in estimating exposure to ethylene oxide in a retrospective cohort mortality study. Scand J Work Environ Health 1988;14 suppl 1:29-30.

9. Krantz S, Cherrie JW, Schneider T, Öhberg I, Kamstrup O. Modeling of past exposure to MMMF in the European rock/slag wool industry. Solna: National Institute of Occupational Health, 1991. Arbete och Hälsa 1991:1.

10. Fidler AT, Baker EL, Letz RE. Estimation of long term exposure to mixed solvents from questionnaire data: a tool for epidemiological investigations. $\mathrm{Br}$ J Ind Med 1987; $44: 133-41$.

11. Gray CN, Gerin M. Retrospective estimation of exposure to welding fumes. In: International Agency for Research on Cancer (IARC). Mortality and cancer incidence follow-up of an historical cohort of European welders. Lyon: IARC, 1989. IARC Internal technical report, no 89/003.

12. IARC Working Group. Phenoxy acid herbicides and contaminants: description of the IARC international register of workers. Am J Ind Med 1990;18:39-45.

13. Saracci R, Kogevinas M, Bertazzi PA, Bueno de Mesquita BH, Coggon D, Green L, et al. Cancer mortality in workers exposed to chlorophenoxy herbicides and chlorophenols. Lancet 1991;338:1027-32.

14. Kauppinen $T$, Kogevinas M, Johnson E, Becher $H$, Bertazzi PA, Bueno de Mesquita B, et al. Chemical exposure in manufacture of phenoxy herbicides and chlorophenols, and in spraying of phenoxy herbicides. Am J Ind Med 1993;23:903-20.

15. Kogevinas M, Winkelman R, Saracci R, Kauppinen T. Cancer mortality in an international cohort of workers exposed to chlorophenoxy herbicides, chlorophenols and contaminants. Lyon: International Agency for 
Research on Cancer (IARC), 1992. IARC internal report, no $92 / 002$.

16. International Agency for Research on Cancer (IARC). Some halogenated hydrocarbons and pesticide exposures. Lyon: IARC, 1986. IARC Monographs on the evaluation of the carcinogenic risk of chemicals to humans, vol 41.

17. Smith TJ, Hammond C, Hallock M, Woskie S. Exposure assessment for epidemiology: characteristics of exposure. Appl Occup Environ Hyg 1991;6:441-7.

18. Ashe WF, Suskind RR. Report - patients from Monsanto Chemical Company, Nitro, West Virginia. Internal Monsanto report (December 5, 1949).

19. Ashe WF, Suskind RR. Progress report - patients from Monsanto Chemical Company, Nitro, West Virginia. Internal Monsanto report (April 1950).

20. Goldman PJ. Schwerste akute Chlorakne durch Trichlorphenol - Zersetzungsprodukte. Arbeitsmed Sozialmed Arbeitshyg 1972;7:12-8.

21. Goldman PJ. Schwerste akute Chlorakne, ein Mass- intoxikation durch 2,3,7,8-tetrachlordibenzodioxin. Hautartz 1973;24:149-52.

22. Marlow DA, Fingerhut MA. Dioxin Registry report: report prepared by review of documents from the Diamond Shamrock Corp, Diamond Alkali Company, Newark, New Jersey. Cincinnati, OH: National Institute for Occupational Safety and Health, June 1986. NTIS \# PB87-222808.

23. Seixas NS, Robins TG, Becker M. A novel approach to the characterization of cumulative exposure for the study of chronic occupational diseases. Am J Epidemiol 1993;137:463-71.

24. Rappaport SM. Selection of the measures of exposure for epidemiology studies. Appl Occup Environ Hyg 1991;6:448-57.

25. Esmen N. Retrospective industrial hygiene surveys. Am Ind Hyg Assoc J 1979;40:58-65.

Received for publication: 8 November 1993 